\title{
Cervical spinal cord infarct associated with patent foramen ovale
}

\author{
Infarto medular cervical associado a forame oval patente \\ Renan Barros Domingues ${ }^{1,2}$, Mayara Ferreira Vilas-Novas ${ }^{1}$
}

1 Escola Superior de Ciências da Saúde da Santa Casa de Misericórdia de Vitória (EMESCAM), Vitória ES, Brazil;

2 Programa de Pós-graduação em Neurociências, Universidade Federal de Minas Gerais (UFMG), Belo Horizonte MG, Brazil.

Correspondence: Renan Barros Domingues; Rua Prof. Almeida Cousin 125 / sala 1309; 29050-565 Vitória ES - Brasil; E-mail: contato@renandomingues.med.br Conflict of interest: There is no conflict of interest to declare.

Received 15 January 2012; Accepted 23 January 2012

Spinal cord infarct is a rare entity representing only one to two percent of all strokes ${ }^{1,2}$. There are only two previous reports of spinal cord infarct associated with patent foramen ovale (PFO), one in the anterior spinal artery (ASA) distribution and the other in the posterior spinal artery (PSA) ${ }^{3,4}$. Here, we report the case of a woman with spinal cord infarct in which the only possible etiology found was a PFO.

\section{CASE REPORT}

A 20-year-old woman with any previous known disease had a sudden interscapular pain and abdominal paresthesias. One day after that, she noted arms and legs weakness that persisted during the following weeks. Neurological examination revealed mild and symmetric legs, and arms paresis with exaggerated tendon reflexes and bilateral Babinski sign. There were no signs of lemniscal sensory deficits. There was a trunk and four limbs slight reduction of tactile and thermal sensory function. Magnetic resonance imaging (MRI) showed slight asymmetric T2-weighted hypersignals on the central $\mathrm{H}$ region of spinal cord extending from $\mathrm{C} 5$ to $\mathrm{C} 7$, compatible with spinal cord infarct (Fig 1). She was submitted to computed tomography angiography of the thoracic and cervical regions, which was normal. Holter was normal. The transesophageal ecocardiography revealed PFO with paradoxical interatrial shunt (Fig 2). All laboratorial data, including thrombophilias search, antinuclear antibodies, VDRL, sorologies for hepatitis, HIV, HTLV-1, anti-Ro and anti-La, were negative. The cerebrospinal fluid (CSF) analysis was normal. Routine laboratorial tests, including blood cell count, glucose, cholesterol and triglycerides, renal and hepatic function, were normal. Cranial MRI was normal.

Based on these results, acetylsalicylic acid at a dose of $100 \mathrm{mg}$ a day was introduced. Physical rehabilitation was initiated. The patient improved, and a minimal strength deficit and hyperreflexia persisted.

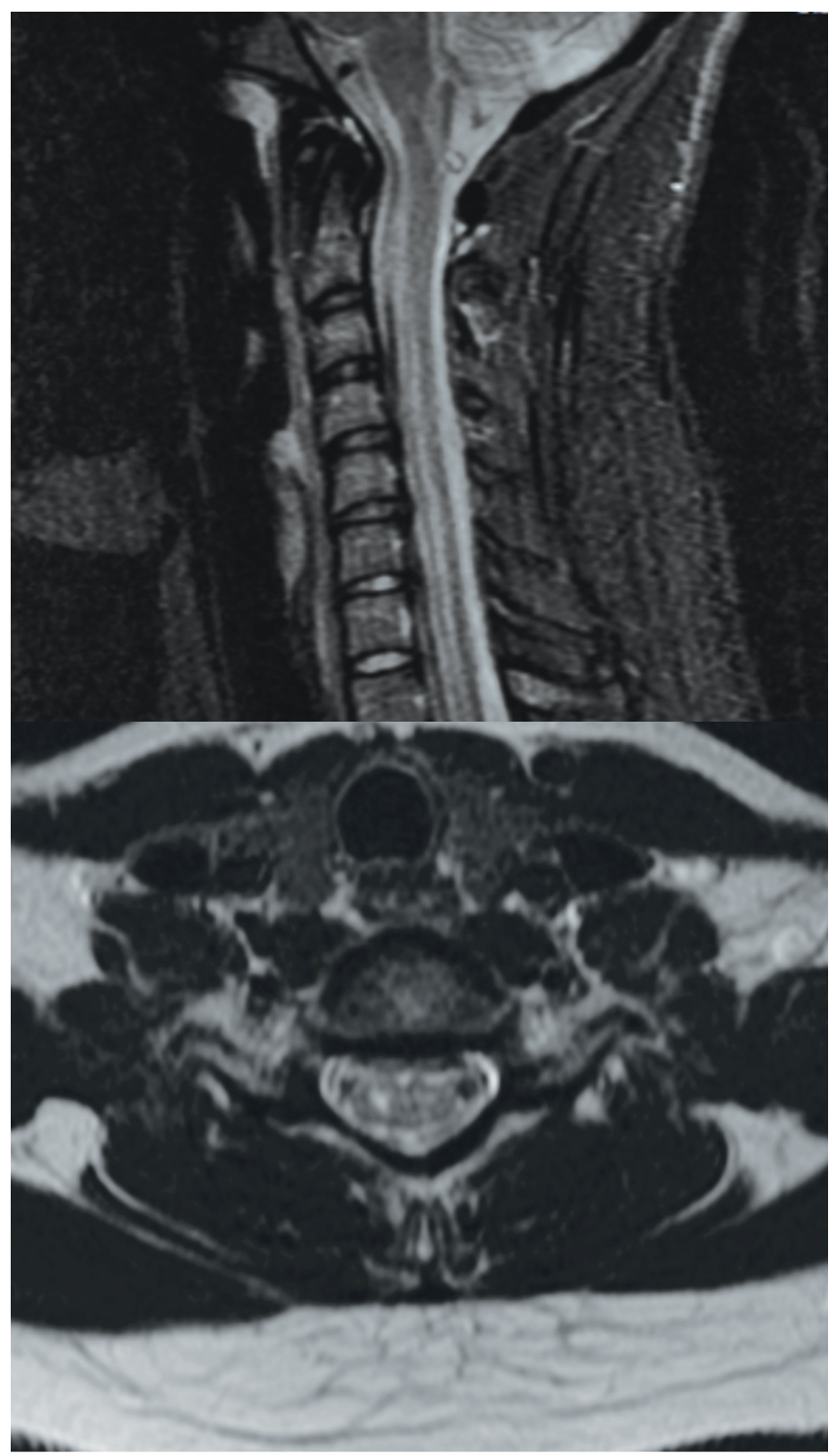

Fig 1. Magnetic resonance imaging showing slight asymmetric $\mathrm{T} 2$-weighted hypersignals on the central $\mathrm{H}$ region of spinal cord extending from $\mathrm{C} 5$ to C7. 


\section{DISCUSSION}

Several diseases that can lead to an acute spinal cord lesion were investigated. Demyelinating diseases were excluded by normal cranial MRI and normal CSF examination. Infection myelitis was excluded by the normal CSF examination and negative serologies. Spinal cord compression and tumors were excluded by the spinal MRI. Also, the spinal MRI was consistent with infarct diagnosis.

Several etiologies of spinal cord infarct were investigated. Aortic and vertebral dissections were excluded by computed tomography angiography. Vasculitis was excluded by normal CSF and negative autoantibodies. There was no risk factor for atherosclerosis. Cervical spine disease was excluded by cervical MRI. There were not triggering movements. The only risk factor found was the PFO.

There are two reported cases of spinal cord infarct associated with PFO, one in ASA territory and other in PSA territory, both in the thoracic region. To our knowledge, this is the first case of cervical spinal cord infarct in the ASA territory associated with PFO already described.

The best approach to prevent recurrences in patients with $\mathrm{PFO}$ is not yet established, but there are reports of treatment with acetylsalicylic acid, warfarin, and closure of $\mathrm{PFO}^{5}$.

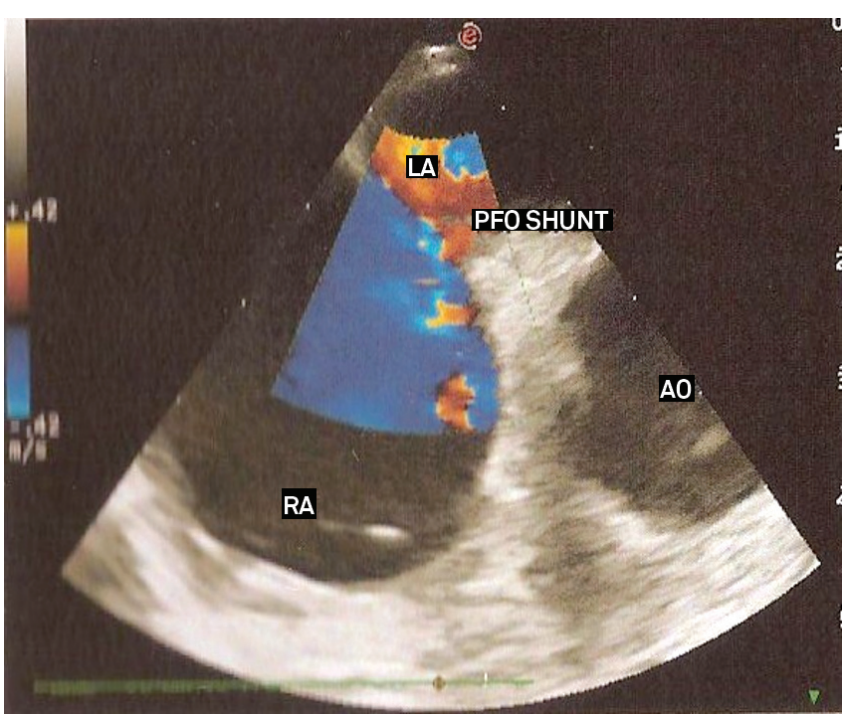

RA: right atrium; LA: left atrium; Ao:Aorta; PFO Shunt: patent foramen ovale shunt.

Fig 2. Transesophageal ecocardiography showing patent foramen ovale with paradoxical interatrial shunt.

This last option was considered due to insufficient evidence. Acetylsalicylic acid was chosen because of the lower risk of bleeding comparing to warfarin.

PFO should be investigated in cases of spinal cord infarct in which the most common etiologies are ruled out.

\title{
References
}

1. Novy J, Caruzzo A, Maeder P, Bogousslavsky J. Spinal cord ischemia: clinical and imaging patterns, pathogenesis, and outcomes in 27 patients. Arch Neurol 2006;63:1113-1120.

2. Kumral E, Polat F, Güllüoglu H, Uzunköprü C, Tuncel R, Alpaydin S. Spinal ischaemic stroke: clinical and radiological findings and short-term outcome. Eur J Neurol 2011;18:232-239.

3. Petruzzellis M, Fraddosio A, Giorelli M, et al. Posterior spinal artery infarct due to patent foramen ovale: a case report. Spine 2010;35:155-158

4. Mori S, Sadoshima S, Tagawa K, lino K, Fujishima M. Massive spinal cord infarction with multiple paradoxical embolism: a case report. Angiology 1993;44:251-256

5. Mattle HP, Meier B, Nedeltchev K. Prevention of stroke in patients with patent foramen ovale. Int J Stroke 2010;5:92-102.

\section{Complex movement disorder in an elderly patient and the chimera effect}

\author{
Distúrbio do movimento complexo em uma paciente idosa e o efeito quimera \\ Marco A. T. Utiumi, Renato P. Munhoz, Caroline Cartaxo, Hélio A. G. Teive \\ Movement Disorders Unit, Neurology Service, Internal Medicine Department, Hospital de Clínicas, Federal University of Paraná (UFPR), Curitiba PR, Brazil. \\ Correspondence: Hélio A. G. Teive; Rua General Carneiro 1103/102; 80060-150 Curitiba PR - Brasil; E-mail:hagteive@mps.com.br \\ Conflict of interest: There is no conflict of interest to declare. \\ Received 27 December 2011; Accepted 03 January 2012
}

Movement disorders (MD) are traditionally divided into hypokinetic syndromes or parkinsonism, and hyperkinetic syndromes, including several involuntary movements, such as chorea, ballism, tremor, tics and dystonia. Complex movement disorder (CMD) is the term used to describe patients presenting with more than one type of movement disorder concomitantly ${ }^{1}$. 